\title{
Engineering training network numerical control processing and remote operation and monitoring
}

\author{
Mo Haijun \\ South China University of Technology \\ Guangzhou, China \\ mohj@scut.edu.cn
}

\author{
Jaing Hua \\ South China University of Technology \\ Guangzhou, China
}

\begin{abstract}
On the basis of numerical control technology, communication technology, computer technology and network technology, the teaching equipments of the Engineering Training Center of South China University of Technology such as the machining centers, CNC lathes, CNC milling machines and the upper control computers are integrated. Through the network, the processing technology assignments, NC program management, process information files, tool parameters, remote monitoring of cutting parameters, as well as the integrated management of students' information, including names, internship jobs, study records, practice assessments, practice test reports, performances, etc. are realized. The information exchanges between the monitoring of laboratory teaching equipments and manufacturing \& processing equipments, students' information and upper control computers are achieved. The research has changed the situation of teaching devices without internet and Independent single processing functions, improved engineering training center teaching facilities, students' information network teaching and management level and enhanced students' practical training skills and work efficiency and level of teaching instructors.
\end{abstract}

Keywords-Engineering Training; CNC machining; Network technology; Remote operation and monitoring

\section{INTRODUCTION}

The Engineering Training Center of South China University of Technology is a national experimental teaching demonstration center. In recent years, the school had increased the investment in Engineering Training Center, acquisition and replacement of a large number of teaching equipment, especially more advanced digital equipment for teaching practice. However, with the increase of the number of teaching equipments and device types, how to strengthen the management and the rational allocation of the equipments, how to give full play to its role in NC machining technology in the process of teaching, how to realize informatization and networking of the NC machine tools, how to realize the construction of the networking platform on the information of students, teaching contents, practice, training reports, student achievement assessments and improve the level of processing technology for manufacturing and the level of network management of students, which have become an important issue that our center are facing.

\section{Present Situation And the Existing Problem}

Currently our center has dozens of $\mathrm{CNC}$ equipments such as machining enters, $\mathrm{CNC}$ lathes, $\mathrm{CNC}$ milling machines, $\mathrm{CNC}$ punching machines, EDM machines, wire cutting machines, laser marking machines, engraving machines, which play an important role in the practice of teaching and production process. However, there are many problems in the use and practice of these numerical control equipments, for example, processing of $\mathrm{CNC}$ machine tools is relatively closed, there is no connection between each laboratory and NC machine tools and the information of the state of the machining tools, machining process and machining results can't be shared. Also, the networking management of $\mathrm{NC}$ programs and communications are not established; the programming and its input of NC lathes are mainly manual; the method of operation is still original, we don't make full use of the powerful network resources function of $\mathrm{CNC}$ machine tools.

The backward management level restricts the development of our center and each teaching equipment is difficult to play a good working efficiency. It is difficult to meet the requirements of the increasingly networking of $\mathrm{NC}$ machines and it is not conducive to the cultivation of innovative talents.

With the rapid development of network technology and advanced manufacturing technology, NC system as an important part of manufacturing unit is also undergoing profound changes and is moving towards an open, networked, intelligent direction and has been widely used in the manufacturing industry. In order to improve the efficiency in the use of $\mathrm{CNC}$ equipments and the practice level of students, universities are making an effort to improve laboratory network management level and realize $\mathrm{CNC}$ machine tools network resource sharing ${ }^{[1,2]}$

Under this background, this paper puts forward the construction and practice of the network teaching platform of the Engineering Training Center. By establishing the network teaching platform with DNC technology, network function of $\mathrm{NC}$ equipments will be enhanced, also realize the information resource sharing of the $\mathrm{NC}$ equipments, the networking management of the student internships performance which will improve the practice achievement management efficiency. Finally, the level of students' network manufacturing and processing technology will be enhanced, which will improve students' engineering practice effect. 


\section{System Key TeCHNOLOGY AND IMPLEMENTATION METHODS}

DNC (Distributed Numerical Control) integrated processing system is a modern mechanical processing operation mode, meaning computer directly or distributed numerical control. It refers to that one or more computers implement digital control on multiple $\mathrm{CNC}$ machine tools. DNC integrated system is a model of automated manufacturing system, the key to the combination of CAD/CAM and computer-aided production management system. It emphasizes the integration of automated information and information flow, material flow control and implementation of Human-Computer Interaction (HCI). DNC is an integrated control system for multiple CNC machine with good flexibility ${ }^{[3,4]}$.

DNC interface is a part of the DNC integrated system, connecting $\mathrm{CNC}$ equipments with industry network for the communication between them. DNC interface architecture is formed with a Net Adapter Card or a modem to connect to the industry network and a Serial Port expansion card to connect to CNC machine, supported by a high-performance general network server, while an appropriate communication and management software are equipped to implement multi serial communication. A communication protocol database and a heterogeneous communication protocol are established to implement a heterogeneous CNC communication system for the communication between different $\mathrm{CNC}$ machines and the industry network through DNC interface using the mature microcomputer network technology. Fig. 1 shows the DNC interface structure ${ }^{[5,6,7]}$.

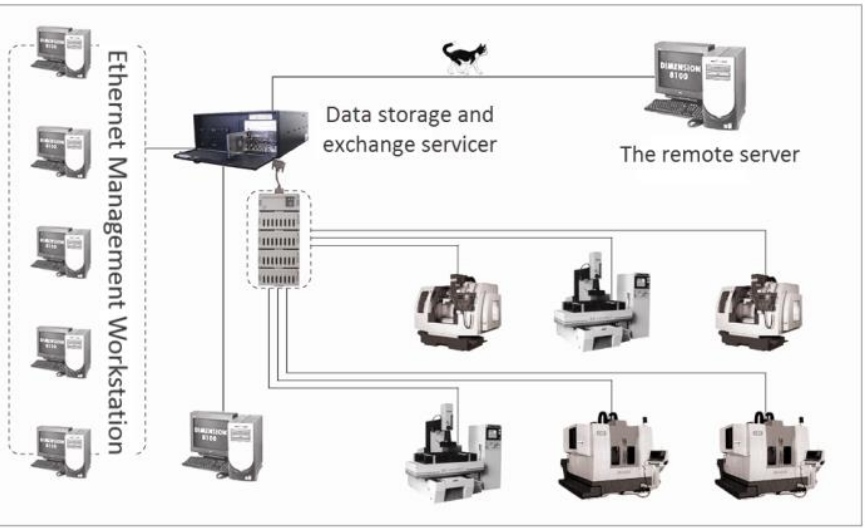

Fig. 1. The DNC interface structure

DNC interface structure involves communication technology and information management technology.

The DNC communication module is the network platform for the NC program which is required for the NC machine in workshop transmission between DNC host and serial port server. Because the NC program is transmitted to multiple NC machines at the same time and it requires the application of multithreading to programming network communication program to support the connection of multiple machines at the same time ${ }^{[8]}$.

Information management is the guarantee for the system operation and it performs an important function in $\mathrm{CNC}$ system.
The core function of a management system is the collection, processing and storing of external data and transferring data outwards. It requires an appropriate information management system to collect process and maintain the data in the database involving all the machining information. In order to manage the data of NC machining, the database structure should involve $\mathrm{NC}$ schedule, the work piece, tool information table, processing tasks table, the device information table and so on. In addition, the system's hard drive stores the extracellular domain of the Internet or this platform editing NC machining program, machining task telegram, the tool and the student's name, grade professional, internship jobs, internships scores and other information which are processed and called on the operation platform in favor of the sharing of resources ${ }^{[9,10]}$.

Only the confirmed legitimate user can login the system by entering the user name and password. Normally, the NC program has three conditions in NC machining: editing, debugging and setting. We can define and manage the approval process of NC program and user privileges for different users having different rights of $\mathrm{NC}$ program under different conditions. It is shown in Fig. 2.

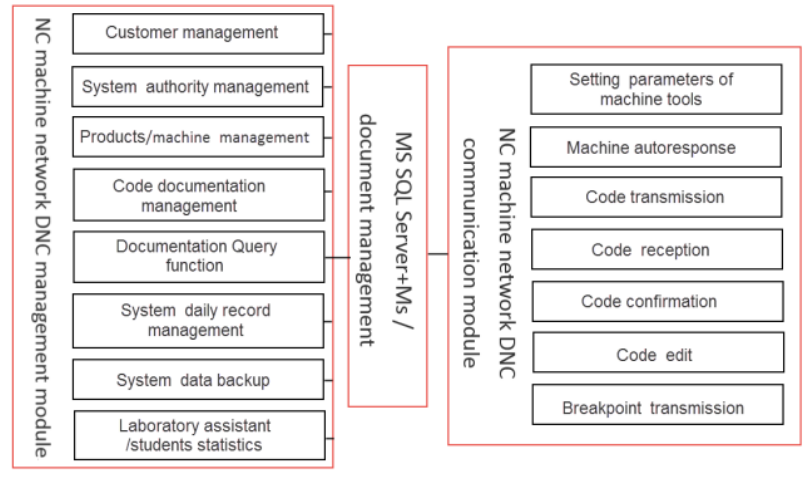

Fig. 2. DNS management module

In the numerical control equipment integrated environment, we need underlying communication in DNC system, namely DNC communications between the host and CNC machine tools to achieve information transmission and processing status feedback of manufacturing information. The key technology of the CNC machine network is the method of integration. The communication depends on the communication interface and communication protocol of the CNC system. Because of the interface of the most CNC equipments in our country, the project uses protocol conversion network control program. It is shown in Fig. 3.

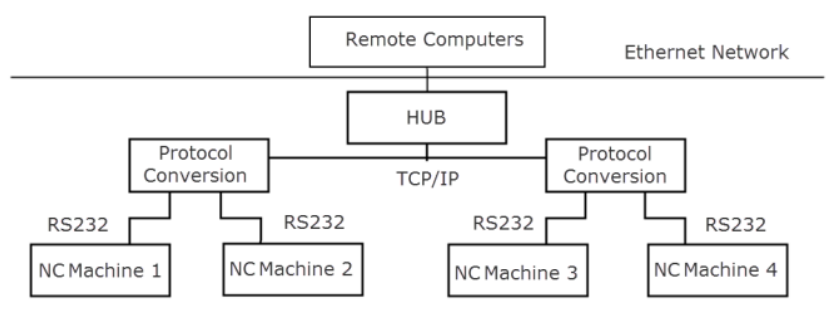

Fig. 3. Protocol conversion network control program 
The remote computer links with the protocol conversion module from RJ-45 card port via Ethernet and connects to NC machines after the protocol conversion. The Ethernet TCP/IP and RS-232C serial protocol conversion are already modularized. A serial port server with convenience of management and maintenance can implement the protocol conversion function well, so that the system has high reliability and stability.

\section{EXAMPLE ANALYSIS}

\section{A. Monitor the operation rate of $\mathrm{CNC}$ machine}

In this page, you can scan machine conditions, operation time and work piece processing conditions, etc. The page refreshes every 10 seconds. Fig. 4 shows the time state diagram of single machine.
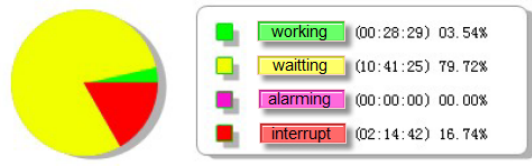

Time state diagram of single machine(24hours) Date:2014-5-15

Time:11:10:18

\begin{tabular}{|c|c|c|c|c|c|}
\hline Machine & & & Workpieos & Workpiese & Curent tate of maxhine \\
\hline 15 & $2014-5-15 \quad 10: 56: 44$ & 1 & $000: 01: 17$ & 380 & waitting \\
\hline 15 & $2014-5-15 \quad 10: 57: 16$ & 1 & 000:01:17 & 380 & working \\
\hline 15 & $2014-5-15 \quad 10: 58: 36$ & 1 & $000: 01: 17$ & 381 & waitting \\
\hline 15 & $2014-5-15 \quad 10: 59: 00$ & 1 & $000: 01: 17$ & 381 & working \\
\hline 15 & $2014-5-15 \quad 11: 00: 20$ & 1 & $000: 01: 17$ & 382 & waitting \\
\hline 15 & $2014-5-15$ 11:02:20 & 1 & $000: 01: 17$ & 382 & working \\
\hline 15 & 2014-5-15 11:03:33 & 1 & 000:01:17 & 383 & waitting \\
\hline 15 & $2014-5-15$ 11:04:53 & 1 & $000: 01: 17$ & 383 & working \\
\hline 15 & $2014-5-15$ 11:06:13 & 1 & 000:01:17 & 384 & waitting \\
\hline 15 & $2014-5-15 \quad 11: 07: 25$ & 1 & $000: 01: 17$ & 384 & working \\
\hline 15 & $2014-5-15 \quad 11: 08: 45$ & 1 & $000: 01: 17$ & 385 & waitting \\
\hline 15 & 2014-5-15 11:09:09 & 1 & 000:01:17 & 385 & working \\
\hline
\end{tabular}

Fig. 4. Time state diagram of single machine

Meanwhile, you can also monitor all the CNC machines through a large screen, monitoring different machines working state in different time and the instant state diagram. Usually we set it to refresh every 10 seconds. It is shown in Fig. 5.

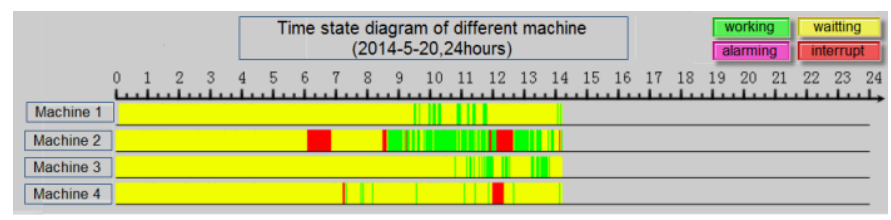

Fig. 5. Time state diagram of different machine

\section{B. Tools Historical Record and Tools Life Management}

The system has detail information of tools, such as the total processing time of each tool in a day. If we change the tools, the tool life management program will delete all the record before the operation. If the tool life management is off, the setting of program deciding how many tool records to be stored. It is shown in Fig. 6.

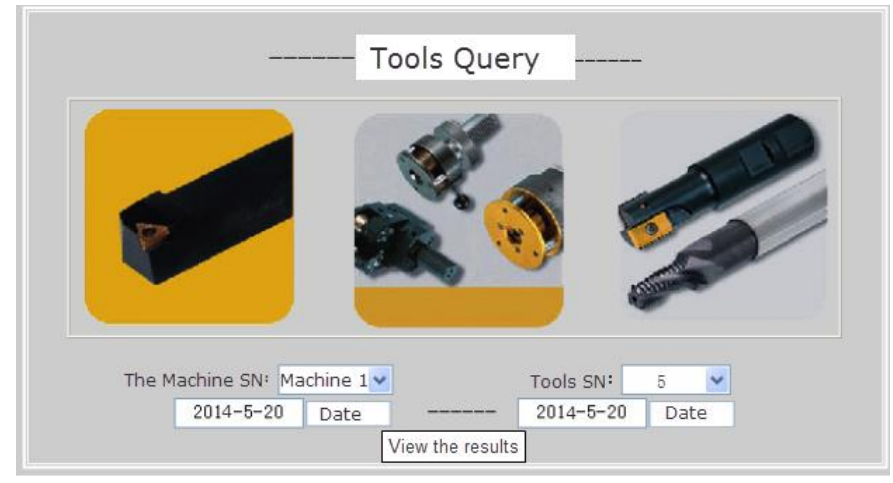

Fig. 6. Tools query

At the same time, you can track the life of the tools being used in CNC machine, so that you can discovery the problem in time to improve tool life and feedback information to purchasing department. It is shown in Tab. 1.

TABLE I. LIFE TRACKING

\begin{tabular}{|c|c|c|c|c|c|c|c|c|}
\hline SN & Tool number & Tool name & Tool position & Number & \begin{tabular}{|c} 
Setting \\
Tool lifetime
\end{tabular} & $\begin{array}{l}\text { Using time } \\
\text { (hours) }\end{array}$ & $\begin{array}{l}\text { Average } \\
\text { lifetime }\end{array}$ & \begin{tabular}{|l|l}
$\begin{array}{l}\text { History } \\
\text { lifetime }\end{array}$ \\
\end{tabular} \\
\hline 1 & \begin{tabular}{|l|} 
TT-20100909XZ \\
\end{tabular} & Boring cutter & 10 & 2 & 200 & 18.84 & 196.23 & Look over \\
\hline 2 & \begin{tabular}{|l}
$T T-20100912 X X$ \\
\end{tabular} & Milling cutter & 15 & 1 & 200 & 22.03 & 200.83 & Look over \\
\hline 3 & \begin{tabular}{|l|} 
TT-20100903XZ \\
\end{tabular} & Boring cutter & 8 & 7 & 200 & 5.66 & 204.3 & Look over \\
\hline 4 & \begin{tabular}{|l|} 
TT-20100908XY \\
\end{tabular} & Boring cutter & 12 & 1 & 200 & 2.25 & 235.6 & Look over \\
\hline 5 & TT-20100kly & Boring cutter & 5 & 3 & 200 & 1.79 & 201.56 & Look over \\
\hline 6 & LXD-12-100-01 & $\begin{array}{c}\text { Vertical milling } \\
\text { cutter }\end{array}$ & 1 & 1 & 200 & 29.97 & & \\
\hline 7 & SZ-100-M5-01 & screw tap M6 & 1 & 4 & 200 & 11.93 & 196.44 & Look over \\
\hline
\end{tabular}

\section{CONCLUSIONS}

This system provides a simple, reliable NC machine network technology and manufacturing information management, performance management system. It completely changes the traditional NC machine tools' manually inputting program and single input, independent operation, single process of manufacturing and other functions, also can realize the remote control and remote service, carry out the information collection of remote processing and performance management, making the CNC machine tool have the network communication function of two-way, high-speed and ensuring the flow of information communication between the laboratories, the bottom and top of the laboratories. Under the environment of network, we connect each laboratory with different NC resources, which will realize the communication between the laboratories, information sharing, resource sharing and mutual cooperation. It will improve the informatization level of the engineering training center, adapt to the competitive society, and greatly improve the level of engineering training teaching.

\section{REFERENCES}

[1] Chang Guoquan,Feng Huiling. Design and Implementation of CNC Machine Tools Network Interface Module[J], Manufacturing Technology \& Machine Tool,2015,1:162-165.

[2] Hu Yuhui. NC network machining[J], Machinery Design \& Manufacture,2011,2:257-259.

[3] Guo Xiaojun, Wang Taiyong, Study on Technology of Network Monitoring in NC Manufacturing Process[J]. Modular Machine Tool \& Automatic Manufacturing Technique, 2008, 9: 56-62. 
[4] Gong Zheng, Research on NC Machine Tool Processing Condition Information Collection and Processing Technology Based on Embedded Systems[D],Dalian Jiaotong Univversity,2010.

[5] Zhang Shuguang. Research on The Remote Monitoring in Processing Systems of NC Machine Based on Network Technology[D],Shengyang Ligong University,2009.

[6] Lu Hong, Li Yizhi. Key Technology of NC Processing System based on the Network DNC, http://www.paper.edu.cn.

[7] Shi Jixiang, Ren Zuping. Study and Implementation of CNC Network Based on Networked Manufacturing Lab[J],Machine Building \& Automation,2007, 36 (4) : 78-80.
[8] Sun Xingwei, Chen Linping, Wang Ke. Research on Network Control NC Machine Tool Based on Ethernet, Modular Machine Tool \& Automatic Manufacturing Technique, 2009, 7:41-43.

[9] Fu Changping,E Mingcheng,Wang Heng. Development of Open CNC System Based on Networked Manufacturing[M], MIE of China,2007,36(1):60-63.

[10] Zhang Tao, Yang Feng, Zhang Lin. The Analyze And Research About The Network of CNC Machine[J],Manufacture Information Engineering of China,2008,37(13): 56-62. 